C. STEENECK*, O. KINZEL, S. ANDERHUB, M. HORNBERGER, S. PINTO, B. MORSCHHAEUSER, F. BRAUN, G. KLEYMANN, T. HOFFMANN (PHENEX PHARMACEUTICALS AG, HEIDELBERG, GERMANY)

Discovery of Hydroxyamidine Based Inhibitors of IDO1 for Cancer Immunotherapy with Reduced Potential for Glucuronidation ACS Med. Chem. Lett. 2020, 11, 179-187.

\section{Synthesis of an Indoleamine-2,3-dioxygenase-1 (IDO1) Inhibitor}<smiles>Nc1nonc1N</smiles>
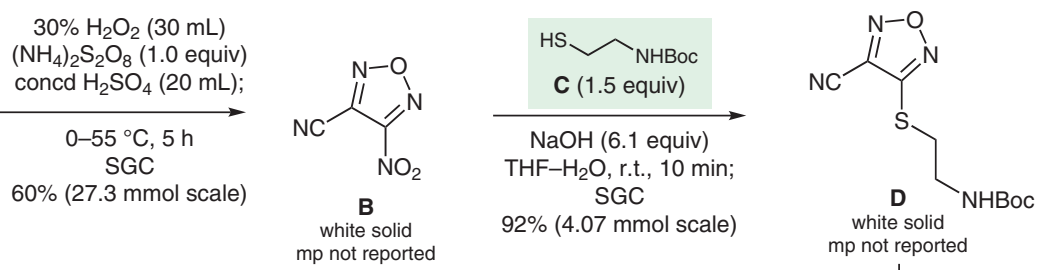

DIBAL-H (5.0 equiv) $-78 \%$
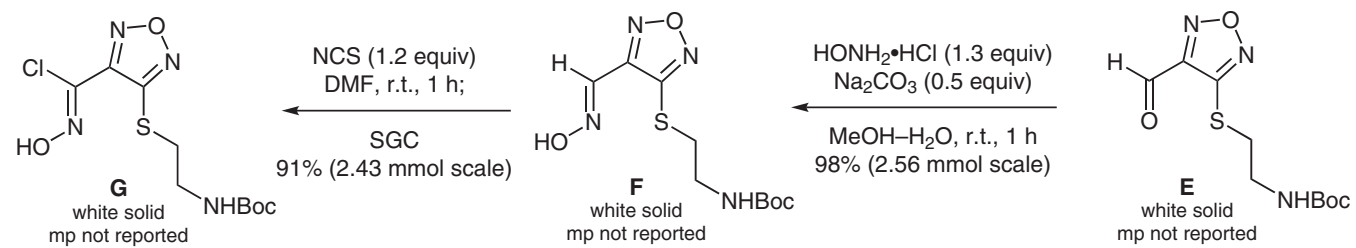

$\mathrm{NH}_{2} \bullet \mathrm{HCl}(1.3$ equiv)

$\mathrm{MeOH}-\mathrm{H}_{2} \mathrm{O}$, r.t., $1 \mathrm{~h}$ $98 \%$ (2.56 mmol scale)
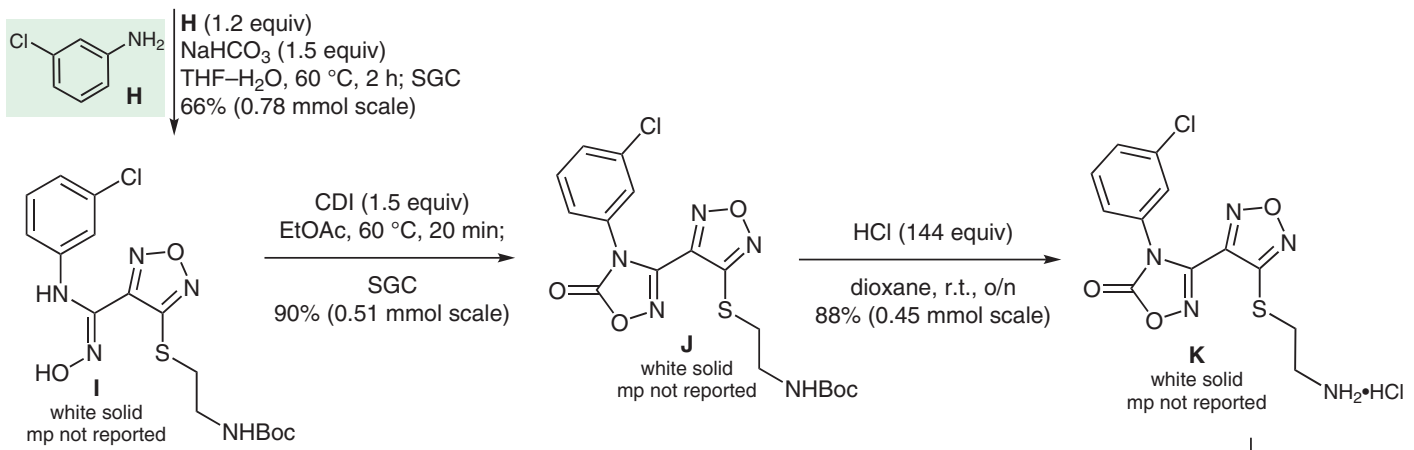<smiles>CCSc1nonc1/C(=N/O)Nc1cccc(Cl)c1</smiles>

N
white solid $\mathrm{mp}$ not reported
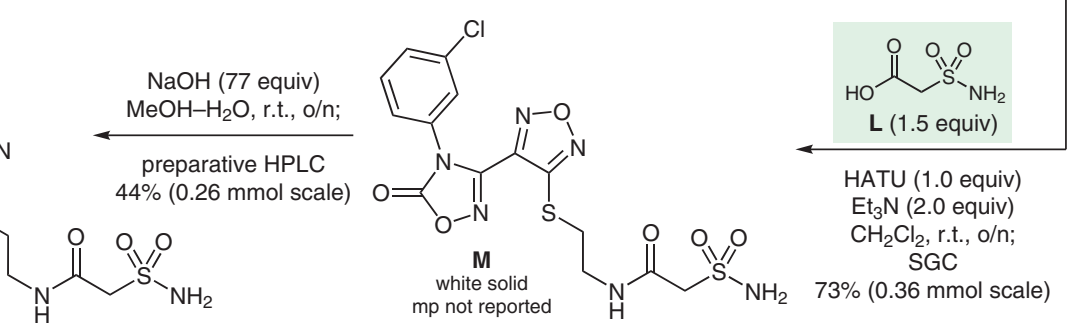

Category

Synthesis of Natural

Products and

Potential Drugs

\section{Key words}

indoleamine-2,3-

dioxygenase-1

inhibitor

1,2,4-oxadiazole

$\mathrm{S}_{\mathrm{N}} \mathrm{Ar}$ reaction
Significance: Indoleamine-2,3-dioxygenase-1 (IDO1) is strongly involved in tumor immune resistance. The immune suppressive effect of IDO1 results from its capacity to degrade tryptophan to $\mathrm{N}$-formylkyurenine, the first and rate-limiting step of the kyurenine pathway. The target molecule $\mathbf{N}$ is a low-nanomolar IDO1 inhibitor.
Comment: Reaction of aldoxime $\mathbf{F}$ with $\mathrm{N}$-chlorosuccinimide (NCS) afforded $N$-hydroxycarbimidoyl chloride $\mathbf{G}$. Treatment of $\mathbf{G}$ with 3-chloroaniline followed by hydroxyamidine cyclization using 1,1'carbonyldiimidazole (CDI) and Boc deprotection afforded the key amino intermediate $\mathbf{K}$. 